\title{
Analysis of foundation sliding of an arch dam considering the hydromechanical behavior
}

\author{
Maria Luísa Braga FARINHA ${ }^{a}$, José Vieira de LEMOS $^{\text {a,* }}$, Emanuel MARANHA DAS NEVES ${ }^{b}$ \\ ${ }^{a}$ LNEC - National Laboratory for Civil Engineering, Av. Brasil 101, Lisboa 1700-066, Portugal \\ ${ }^{b}$ IST - Instituto Superior Técnico, Av. Rovisco Pais 1, Lisboa 1049-001, Portugal \\ ${ }^{*}$ Corresponding author. E-mail: vlemos@lnec.pt
}

(C) Higher Education Press and Springer-Verlag Berlin Heidelberg 2012

\begin{abstract}
This paper presents the application of a methodology which can be used to assess arch dam foundation stability, using the discrete element method (DEM) and the code 3DEC. A global three-dimensional model of a dam foundation was developed, in which some discontinuities were simulated and both the grout and drainage curtains were represented. The model, calibrated taking into account recorded data, was used to carry out nonlinear mechanical analysis. The same model was employed to perform a hydraulic analysis, based on equivalent continuum concepts, which allowed the water pressure pattern within the foundation to be obtained. These water pressures were applied on discontinuities involved in the possible sliding mechanism along the dam/foundation interface, and the safety of the dam/foundation system was evaluated using a process of reduction of strength characteristics, with the aim of calculating the minimum safety factors that ensure stability. Results were compared with those obtained with the usual bi-linear uplift pressure distribution at the base of the dam, commonly used in concrete dam design. The relevance of carrying out hydraulic analysis in arch dam foundation failure studies is highlighted.
\end{abstract}

KEYWORDS concrete dams, rock foundations, hydromechanical behavior, failure analysis

\section{Introduction}

In concrete dam foundations, failure mechanisms are typically defined by natural rock discontinuities, the dam/ foundation interface or strata with lower strength. Instability may occur underneath the dam, in the abutments or in adjacent slopes. In the case of arch dam foundations, special attention must be given to failure scenarios associated with sliding along weaker surfaces in the dam foundation area where the arches rest, particularly in the valley sides and in the abutments, and to those involving seepage in the valley bottom, which leads to erosion of discontinuities.

Stability analysis for scenarios of foundation failure is often based on simplified limiting equilibrium procedures. More advanced analysis, however, is carried out with the DEM, which allows the discontinuous nature of rock to be properly simulated, and which may include fluid flow

Article history: Received September 10, 2011; Accepted October 31, 2011 through the discontinuities. Stability studies using discontinuum models that take into account the coupling between hydraulic and mechanical effects have been applied mainly in two-dimensional (2D) analysis, for gravity dams [1,2]. However, for arch dams threedimensional (3D) analysis is always required. In this case, fracture flow models become difficult to employ, but this can be overcome by performing stability evaluation applying suitable water pressures on potential sliding surfaces, calculated with a simple uncoupled flow analysis, in order to provide worst case scenarios [3]. Lemos and Antunes used DEM to perform the safety analysis of two large Portuguese arch dams recently designed and currently under construction [4], assuming the usual bilinear diagram of water pressures at the base of the dam and a simplified pressure field downstream from the dam, defined in terms of a water table compatible with the valley slopes.

Regarding the concrete structure, Feng et al. [5] have recently presented a procedure for the safety evaluation of high arch dams. These authors propose the use of a set of 
safety factors for evaluation of both the curtain safety at the heel of the dam and the ultimate bearing capacity of high arch dams. A comparative study was carried out among the Kölnbrein, Ertan and Xiaowan arch dams, which allowed an evaluation criterion of the safety factors to be suggested.

This paper presents a study on mechanical behavior and seepage in Alqueva arch dam foundation carried out with a view to evaluating dam stability. A global 3D numerical model of the dam and foundation was developed, with which it is possible to perform both mechanical and hydraulic analysis. The latter, based on equivalent continuum concepts, was done in order to obtain the water pressure pattern within the foundation, including pressures on discontinuities involved in possible sliding block mechanisms. These water pressures were afterwards applied in the 3D discontinuum mechanical model of the dam foundation, and the stability of the dam/foundation system was analyzed for the failure scenario of sliding along the dam/foundation interface.

\section{Alqueva arch dam}

Alqueva dam (Fig. 1) creates the largest artificial lake in Western Europe, with storage capacity of $4150 \mathrm{hm}^{3}$ and a surface area of $250 \mathrm{~km}^{2}$ at the retention water level. The dam is located on the River Guadiana, in the south-east of Portugal, and is the main structure of a multipurpose development designed for irrigation, energy production and water supply. It is a double curvature arch dam, with a maximum height of $96 \mathrm{~m}$ and a total length of $348 \mathrm{~m}$ between the abutments at the crest elevation $(154 \mathrm{~m})$. The dam width is $7 \mathrm{~m}$ at the crest, while at the base it varies from $30 \mathrm{~m}$ at the central cantilever to $33 \mathrm{~m}$ at the abutments. The powerhouse is located at the toe of the dam with a dam-wall downstream. In the valley bottom there is an impervious slab between the arch and the damwall (substation slab), and thus, in this area, the dam length in the upstream-downstream direction is $140 \mathrm{~m}$.

The foundation consists of green schist of good quality on the right bank and the river bottom and of quite good phyllite on the left bank. The area of the phyllite is more fractured and is crossed by several faults, the most important being fault 22, along which the green schist/ phyllite interface occurs. Various sets of subvertical and subhorizontal rock joints were identified at the dam site.

For foundation seepage control, grout and drainage curtains were installed from the foundation gallery of the dam and of the downstream dam-wall. To evaluate the efficiency of the relief system a network of piezometers was installed.

The first filling of the reservoir began in February 2002 and was concluded in January 2010.

\section{Numerical analysis}

\subsection{Model}

Numerical analysis of both concrete dam and rock mass was carried out with the code 3DEC [6], based on the discrete element model, which allows the analysis of the mechanical behavior of both structures and media with discontinuity surfaces and of the hydraulic behavior, assuming that flow takes place either through the discontinuities or through equivalent continuum media.

The failure scenario along the foundation joint was analyzed based on the model shown in Fig. 2, where discontinuities simulating the dam contraction joints, the dam/foundation interface (foundation joint), and two hypothetical joints between the grout curtain and the rock mass, at the upstream and downstream faces of the grout curtain, respectively ("grout curtain/rock interface") were considered (Fig. 3). These latter joints were introduced in order to simulate the opening of vertical fissures within the dam foundation close to the upsteam face of the dam, caused by the existence of tensile stresses that usualy develop within the rock mass below the heel of the dam, due to the filling of the reservoir. It was assumed that discontinuities may exhibit nonlinear behavior,

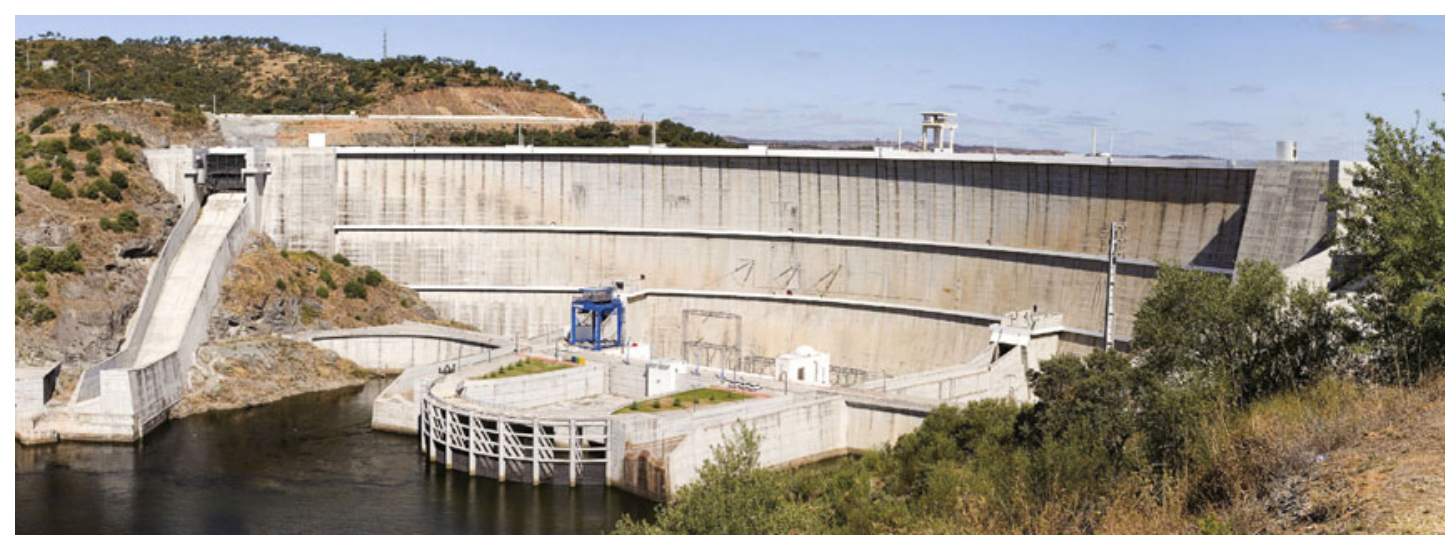

Fig. 1 Downstream view of Alqueva dam 


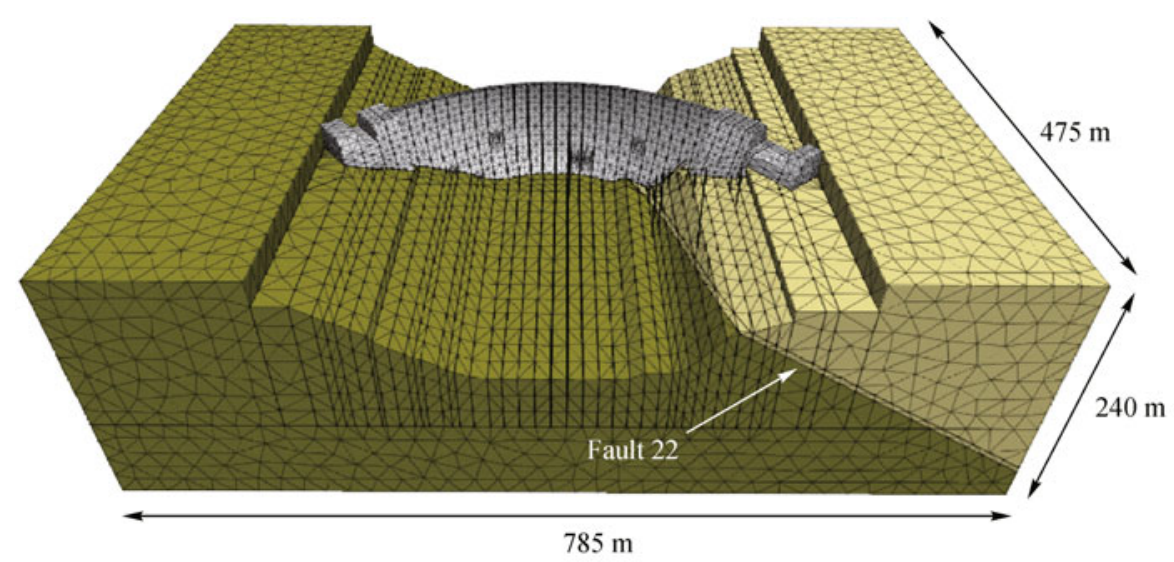

Fig. 2 Geometry of the block system developed to analyze failure along the foundation joint and finite element mesh within the rock mass blocks
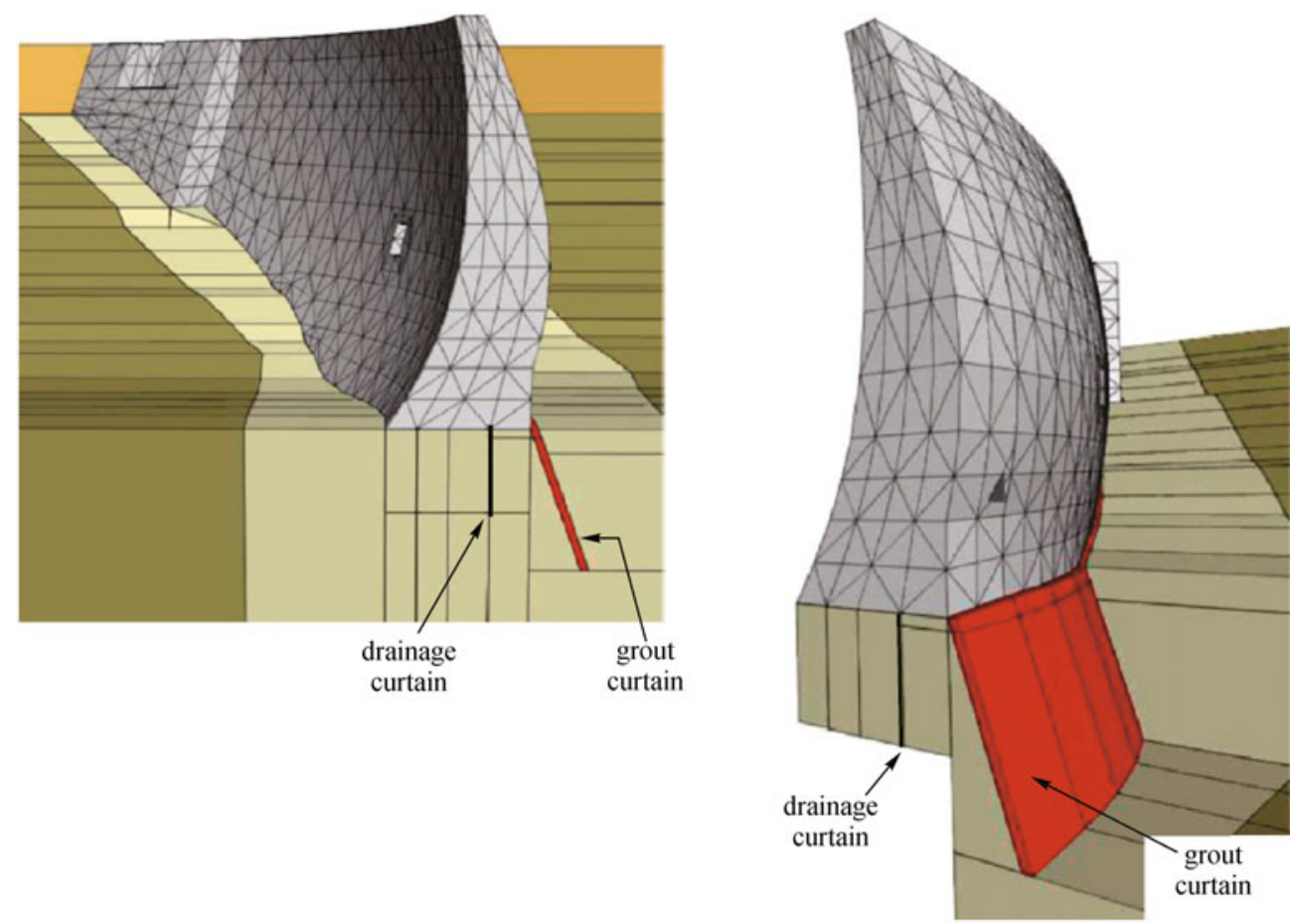

Fig. 3 Global foundation model: cross section with simulated grout and drainage curtains (a) and detail showing the grout and drainage systems (b) (adapted from [7])

(discontinuities' constitutive model embodies the MohrCoulomb failure criterion, complemented with a tensile strength criterion), with failure caused by either tensile or shear stress, and that blocks of both the dam and the rock mass have a linear elastic behavior. The model includes the location of fault 22 , in order to simulate the area of lower modulus of elasticity, where the phyllite occurs. In this model neither the faults nor the rock joints within the rock mass were simulated, and thus the rock mass was assumed as a continuum medium.

It is assumed that dam concrete Young's modulus is
$20 \mathrm{GPa}$ and that the rock mass Young's modulus is $10 \mathrm{GPa}$ where schist occurs and $5 \mathrm{GPa}$ in the phyllite area. Regarding joint deformability, the same normal and shear stiffnesses are assumed in the simulated discontinuities $\left(k_{\mathrm{n}}=10 \mathrm{GPa} / \mathrm{m}\right.$ and $\left.k_{\mathrm{s}}=5 \mathrm{GPa} / \mathrm{m}\right)$. Friction angles of $40^{\circ}$ and $35^{\circ}$ are assumed at the dam contraction joints and at the grout curtain/rock interface, respectively. In these discontinuities, it is assumed that both cohesion and tensile strength are zero. Regarding the foundation joint, various studies have presented strength parameters determined experimentally [8], but the results are widely scattered. In 
this study it is assumed that the foundation joint friction angle is $45^{\circ}$ and that cohesion and tensile strength are $2 \mathrm{MPa}$.

The hydraulic model was developed taking into account field data and the results of several in situ tests which allowed the main seepage paths to be identified $[9,7]$. The grout curtain is modeled adjacent to the upstream edge, not underneath the dam itself, and the drainage system is simulated in a simplified way by a hypothetical continuous trench with the same depth as the drains. In reality, the grout curtain was drilled from the drainage gallery, which is located around $7 \mathrm{~m}$ downstream from the upstream face of the dam. However, the small shift upstream of the grouted area is an acceptable approximation considering the uncertainty regarding both the exact extent and the permeability of the grouted area. The existence of vertical fissures at the heel of the dam is simulated by a nearsurface area of higher permeability upstream from the grout curtain, in the valley bottom and at the base of each slope. Horizontal layers of higher permeability between the above-mentioned near-surface area and the drainage curtain are assumed close to the concrete/rock mass interface to simulate the main seepage paths, as shown in Fig. 4. In the foundation of some of the dam blocks located in the valley bottom, the permeability of the horizontal layers between the near-surface area of higher permeability and the drainage curtain was adjusted in order to obtain numerical discharges close to average discharges recorded with the reservoir at the retention water level $(152 \mathrm{~m})$ and the water downstream from the dam-wall at an elevation of $85.6 \mathrm{~m}$ (reservoir and tailwater levels recorded on the 8th January 2010). The concrete/rock mass interface and the bottom and lateral boundaries are assumed to be impervious. A zero pressure is assumed at the drains' head, which corresponds, at the bottom of the valley, to a hydraulic head of around $61.0 \mathrm{~m}$ along the drainage boreholes.

The model has 2209 blocks (of which 30 are dam blocks) with 80491 nodal points and 11209 contact points, where interaction between blocks takes place. The average edge lengths of the tetrahedral finite elements of the dam foundation are: 1) $4 \mathrm{~m}$ in the blocks surrounding the drainage curtain, 2) $8 \mathrm{~m}$ in the vicinity of the abovementioned blocks, including the grout curtain area, 3) $12 \mathrm{~m}$ in the areas close to the dam in the upstream and downstream direction, and 4) $20 \mathrm{~m}$ in the remaining blocks, including the block at the base of the model. Dam blocks are divided into 442 finite elements of the second degree, with 6999 nodal points, and the foundation blocks into 143676 tetrahedral elements, with 73492 nodal points.

\subsection{Sequence of analysis}

The sequence of analysis included: 1) calculation of in situ stresses due to the weight of the rock mass; 2) consideration of dam weight, and 3) application of hydrostatic loading on the upstream face of the dam and on the foundation discontinuities. Each one of these actions was kept constant during numerical analysis.

Regarding water pressures within the foundation, including uplift pressures in the foundation joint, analysis was carried out assuming first that the drainage system was operating properly and then, in a very unfavorable situation, that it was non-operational. Figure 5 shows the calculated uplift pressures in both situations. It should be mentioned that the model takes into account the loss of hydraulic head at the grout curtain area, which is modeled upstream from the dam, and thus the hydraulic head at the

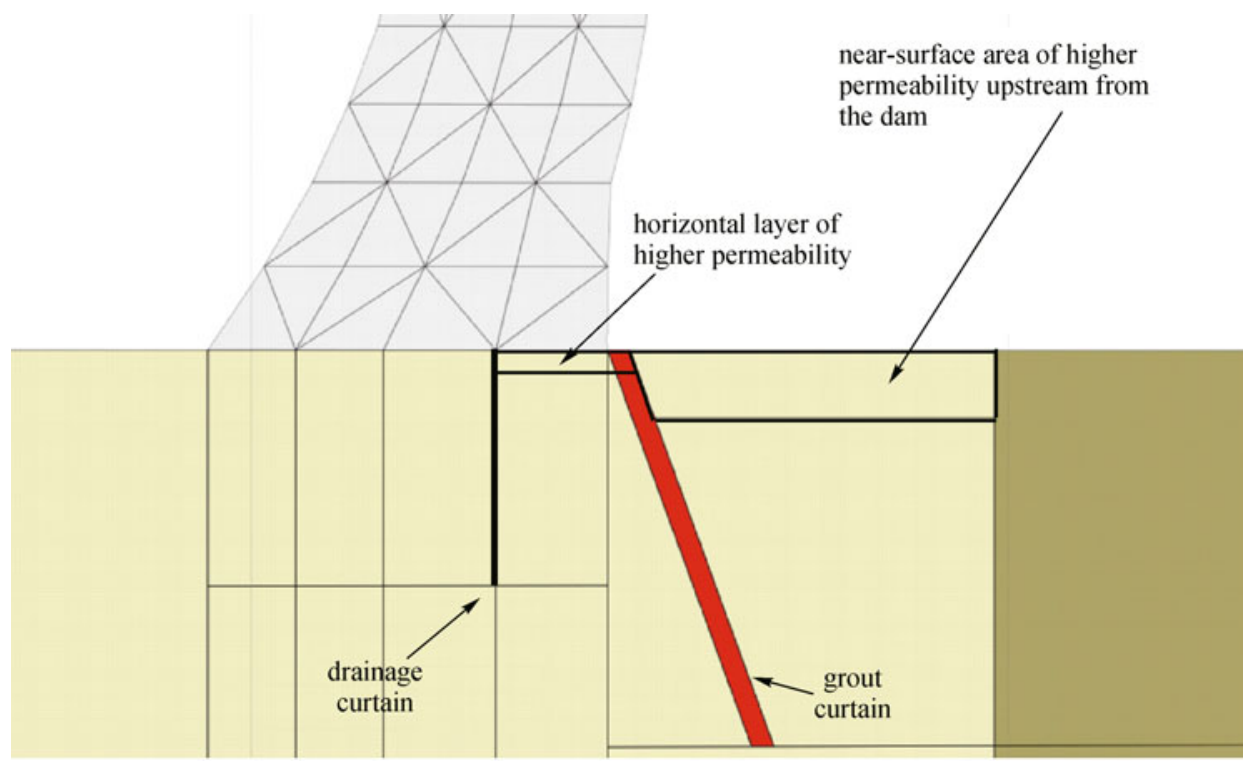

Fig. 4 Cross section of the global foundation model showing the location of the near-surface area of higher permeability upstream from the dam and of the horizontal layers of higher permeability 

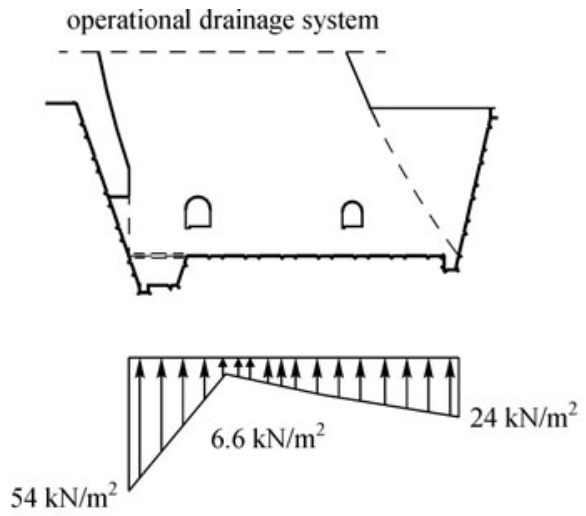
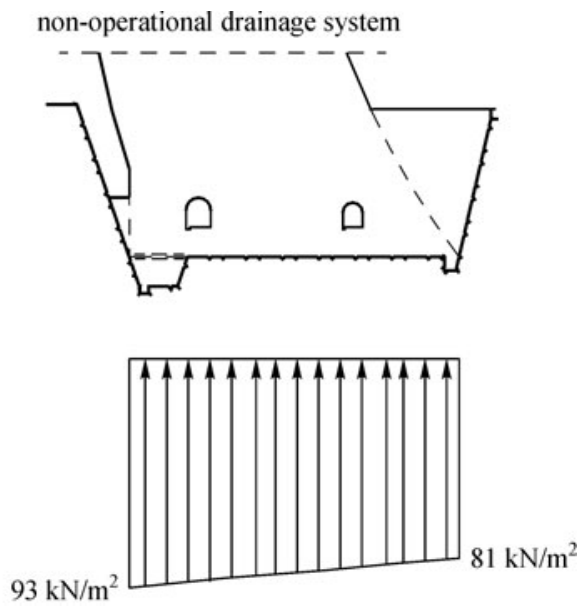

Fig. 5 Calculated uplift pressures on the central cantilever

heel of the dam is lower than full reservoir head $(96 \mathrm{~m})$. The situation with non-operational drainage system is, in this particular case, highly unfavorable, as tailwater head is only assumed downstream from the dam-wall, more than $100 \mathrm{~m}$ away from the toe of the dam, at the valley bottom. Figure 5 shows that, in this case, near full reservoir head is calculated along the base of the dam.

The safety evaluation is done by performing a sequence of analysis in which the strength properties of the discontinuities are progressively reduced. This procedure, which is adequate in discrete element analysis, has the advantage of enabling the evaluation of displacement indicators during the process of strength reduction. In the study presented here, analysis of dam foundation stability began by neglecting the contribution of both cohesion and tensile strength in the foundation joint, but keeping the friction angle of $45^{\circ}(F=1.0)$. The friction angle of the foundation joint was then gradually reduced (the reduction coefficient was applied to the tangent of the friction angle $(\phi))$.

\subsection{Validation of the numerical model}

Comparison of recorded and numerical results with the reservoir at various levels showed that the geomechanical model developed is realistic, simulating the actual dam/ foundation behavior reasonably well. Quite accurate comparisons were achieved concerning: 1) the horizontal displacement at the crest of the central cantilever, 2) vertical displacements at the foundation joint, 3) stresses in the foundation rock mass due to increase in reservoir level, and 4) aperture of the discontinuities through which water flows.

Regarding the first above-mentioned comparison, studies of quantitative interpretation based on recorded displacements in vertical plumb-lines, led to the conclusion that horizontal displacements at the crest of the central cantilever due to hydrostatic loading are about $50 \mathrm{~mm}$ with the reservoir at around $150 \mathrm{~m}$. Numerical horizontal displacements for the same reservoir level are about $90 \%$ of that recorded.

The dam has a peripheral joint in the upstream area of the dam/foundation interface, which is monitored with joint gauges. This peripheral joint was introduced with the aim of avoiding vertical stresses in the foundation with the filling of the reservoir. For reservoir levels of about $150 \mathrm{~m}$, displacements of 0.6 up to $0.92 \mathrm{~mm}$ were recorded in a joint gauge located at the base of the central cantilever. A numerical foundation joint aperture of $0.8 \mathrm{~mm}$ is determined for the reservoir at an elevation of $150 \mathrm{~m}$, which is within the range of recorded displacements.

Double and single rod extensometers are installed below some of the dam blocks. Comparison of recorded and numerical strains in the vertical direction below the central cantilever led to the conclusion that, for the highest reservoir level, calculated strains are about 33\% lower than those recorded.

In one of the dam blocks, recorded discharge increased around eight times (from $0.23 \mathrm{~L} / \mathrm{min}$ up to $1.93 \mathrm{~L} / \mathrm{min}$ ) when the water in the reservoir increased around $28 \mathrm{~m}$. Thus, taking into account the cubic law and assuming that water flowed through a single discontinuity, the discontinuity aperture doubles, due to the above-mentioned increase in reservoir level. Differences in numerical average vertical stresses for the various reservoir levels were used to determine variations in apertures of horizontal water conductive discontinuities below the heel of the dam. It was concluded that accurate results would be obtained if it were assumed that the area below the heel of the dam block was less deformable than the average rock mass deformability modulus assumed in the model.

Concerning the hydraulic behavior, comparison of both numerical and recorded discharges and water pressures showed that the model can provide mean water pressures and flow rates for each dam foundation block. Figure 6 shows how close the total discharges recorded in arch 

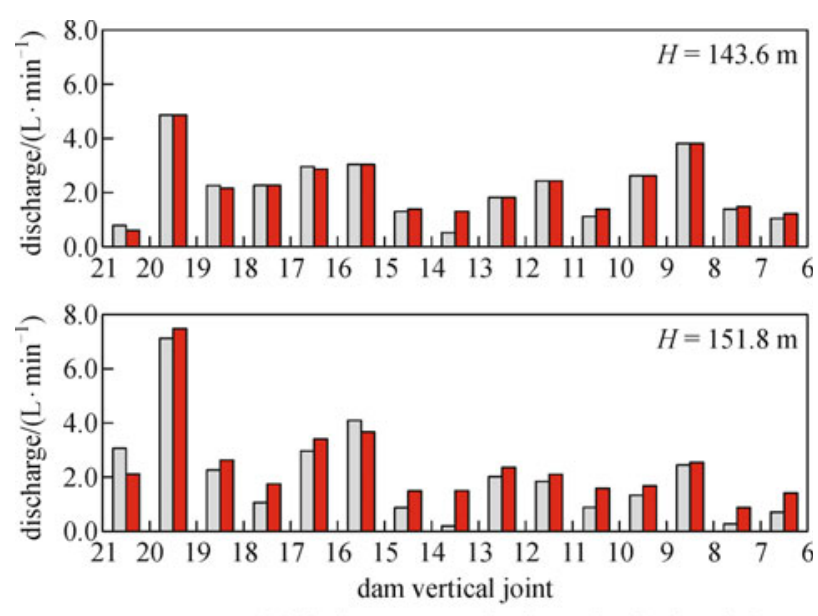

$\square$ recorded discharge $\square$ hydromechanical model

Fig. 6 Recorded discharges in the foundation of each arch block located in the valley bottom and at the base of each slope and comparison with numerical results

blocks located in the valley bottom and at the base of each slope (between dam joints 6 and 21) are to the numerical results obtained with the foundation model developed.

\section{Stability of the dam/foundation interface}

\subsection{Analysis of displacements}

Figures 7 and 8 show the field of displacements obtained on the downstream face of the dam for different $F$, assuming an operational and non-operational drainage system, respectively.

The same failure mechanism is observed in both situations, with sliding of blocks from the right bank at the dam/foundation interface, although for the $F=1.6$ the displacements when the drainage system is not operational are significantly higher. Dam movement is in the upstreamdownstream direction. Only blocks from the right bank have the potential to slide, due to the valley assimetry and to greater height of dam cantilevers in this side of the valley, when compared to the corresponding ones on the left bank. Analysis of displacement histories in various dam points during numerical analysis and analysis of finite element velocities lead to the conclusion that, with an operational drainage system, stress redistribution allows dam equilibrium to be reached again. With a nonoperational drainage system the last stable situation is for $F=1.6$.

Figure 9 shows the variation in dam displacements during the process of reduction of the tangent of the friction angle (these values include displacements due to the dead weight, hydrostatic pressure and uplift pressures). Different curves are shown representing the variation in displacements at the top and at the base of arch blocks. Figure analysis shows that, with an operational drainage system, dam displacements remain almost the same until $F$ $=1.4\left(\phi=35.5^{\circ}\right)$. From this point, gradual increase in displacements is observed until $F=1.9\left(\phi=27.8^{\circ}\right)$, which becomes steeper for $F=2.0$. With a non-operational drainage system, displacements have a moderate increase until $F=1.3$, and a more visible increase for higher values of the reduction factor.
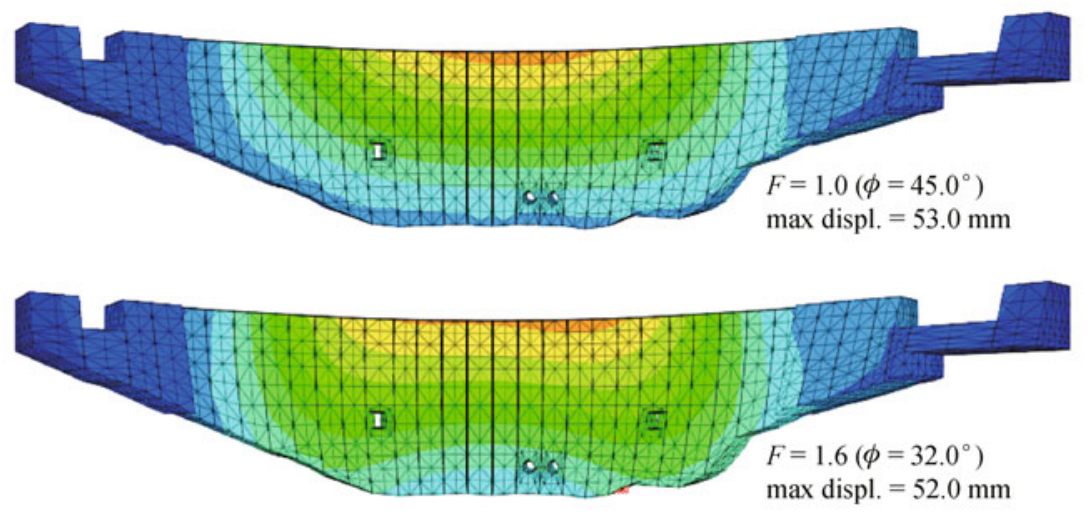

displacement $/ \mathrm{m}$

$0.0000 \mathrm{E}+00$

$5.0000 \mathrm{E}-03$

$1.0000 \mathrm{E}-02$

$1.5000 \mathrm{E}-02$

$2.0000 \mathrm{E}-02$

$2.5000 \mathrm{E}-02$

$3.0000 \mathrm{E}-02$

$3.5000 \mathrm{E}-02$

$4.0000 \mathrm{E}-02$

$4.5000 \mathrm{E}-02$

$5.0000 \mathrm{E}-02$

$5.5000 \mathrm{E}-02$

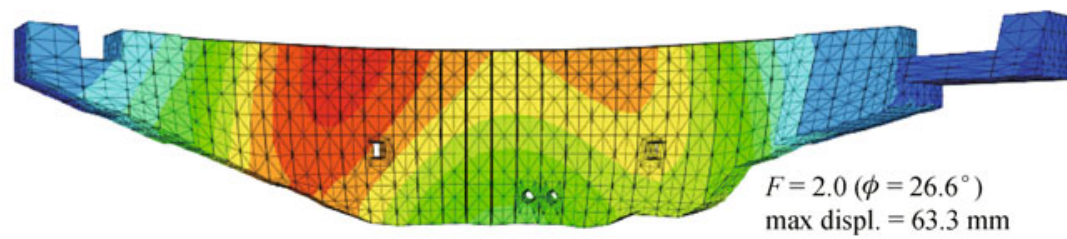

$6.0000 \mathrm{E}-02$

$6.5000 \mathrm{E}-02$

Fig. 7 Displacements at the downstream face of the dam for different friction reduction factors $(F=1.0,1.6$ and 2.0), with an operational drainage system 

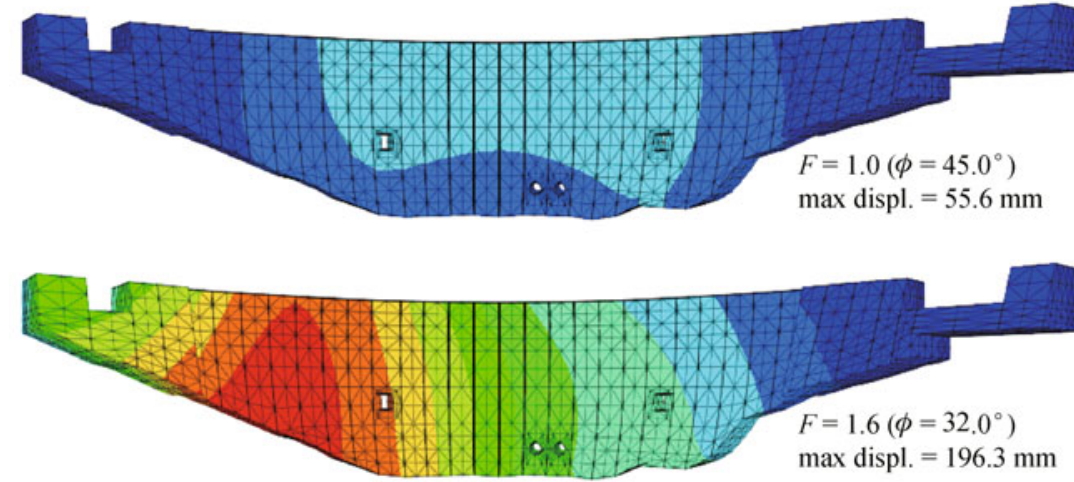

displacement $/ \mathrm{m}$

$0.0000 \mathrm{E}+00$

$2.0000 \mathrm{E}-03$

$4.0000 \mathrm{E}-02$

$6.0000 \mathrm{E}-02$

$8.0000 \mathrm{E}-02$

$1.0000 \mathrm{E}-01$

$1.5000 \mathrm{E}-01$

$1.4000 \mathrm{E}-01$

$1.6000 \mathrm{E}-01$

$1.8000 \mathrm{E}-01$

$2.0000 \mathrm{E}-01$

Fig. 8 Displacements at the downstream face of the dam for different friction reduction factors $(F=1.0$ and 1.6), with a non-operational drainage system

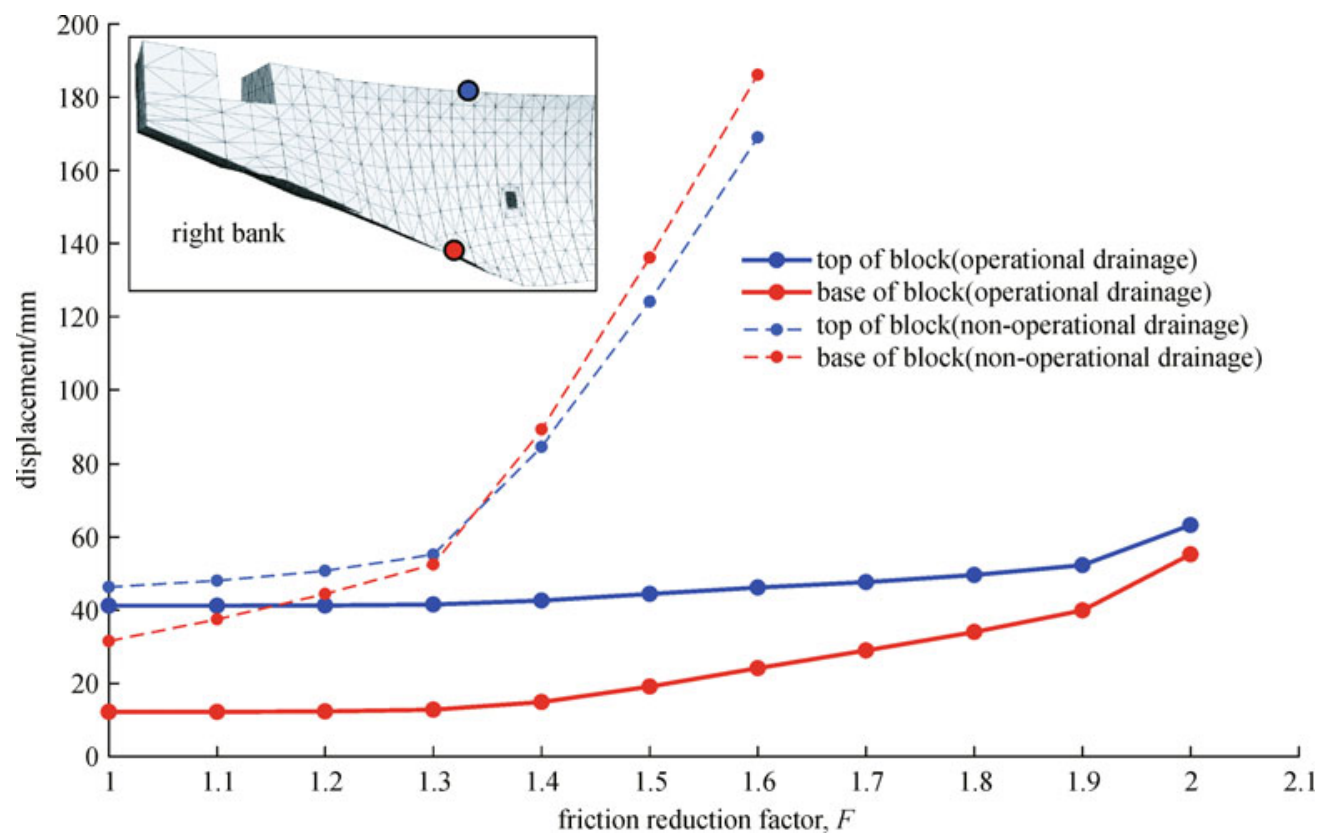

Fig. 9 Variation in displacements at the top and at the base of two different blocks on the right bank, during the process of friction angle reduction, with and without drainage

4.2 Comparison of the results with those obtained using the bi-linear uplift pressure distribution at the base of the dam

At the design stage, it is normal practice to assume full reservoir head at the heel of the dam and zero or tailwater head, if any, at the toe of the dam. At the drainage line the head is regularly assumed to be equal to between one half and one third of the head difference between the heel and toe of the dam. Thus, a bi-linear distribution of the uplift pressure along the base of the dam is assumed. Figure 10 shows the different uplift distributions along the base of the central cantilever obtained with a hydraulic analysis and using design assumptions.
The variation in displacements at the two different dam points, during the process of friction angle reduction, with the different uplift distributions, is shown in Fig. 11. With the bi-linear uplift distribution displacements at the base of the block remain almost unchanged until $F=1.2$, increase until $F=1.7$, and increase further after that. It is concluded that from $F=1.7$ dam behavior is quite different from that obtained with the calculated water pressures.

\section{Conclusions}

This paper presents a study of Alqueva dam using a 

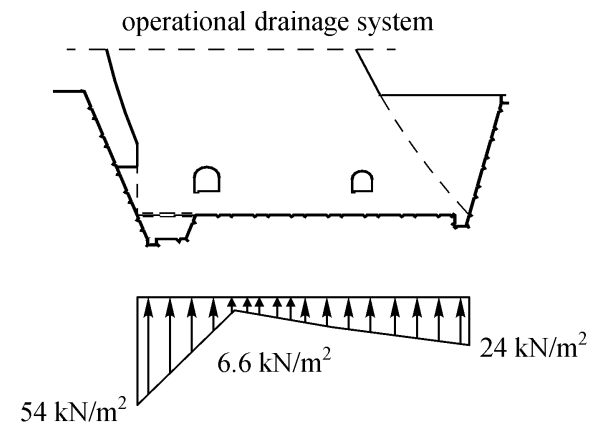
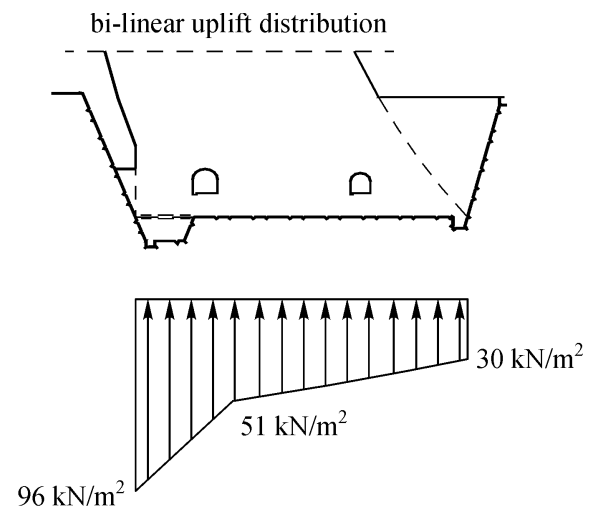

Fig. 10 Calculated uplift pressures with an operational drainage system and bi-linear uplift distribution along the base of the central

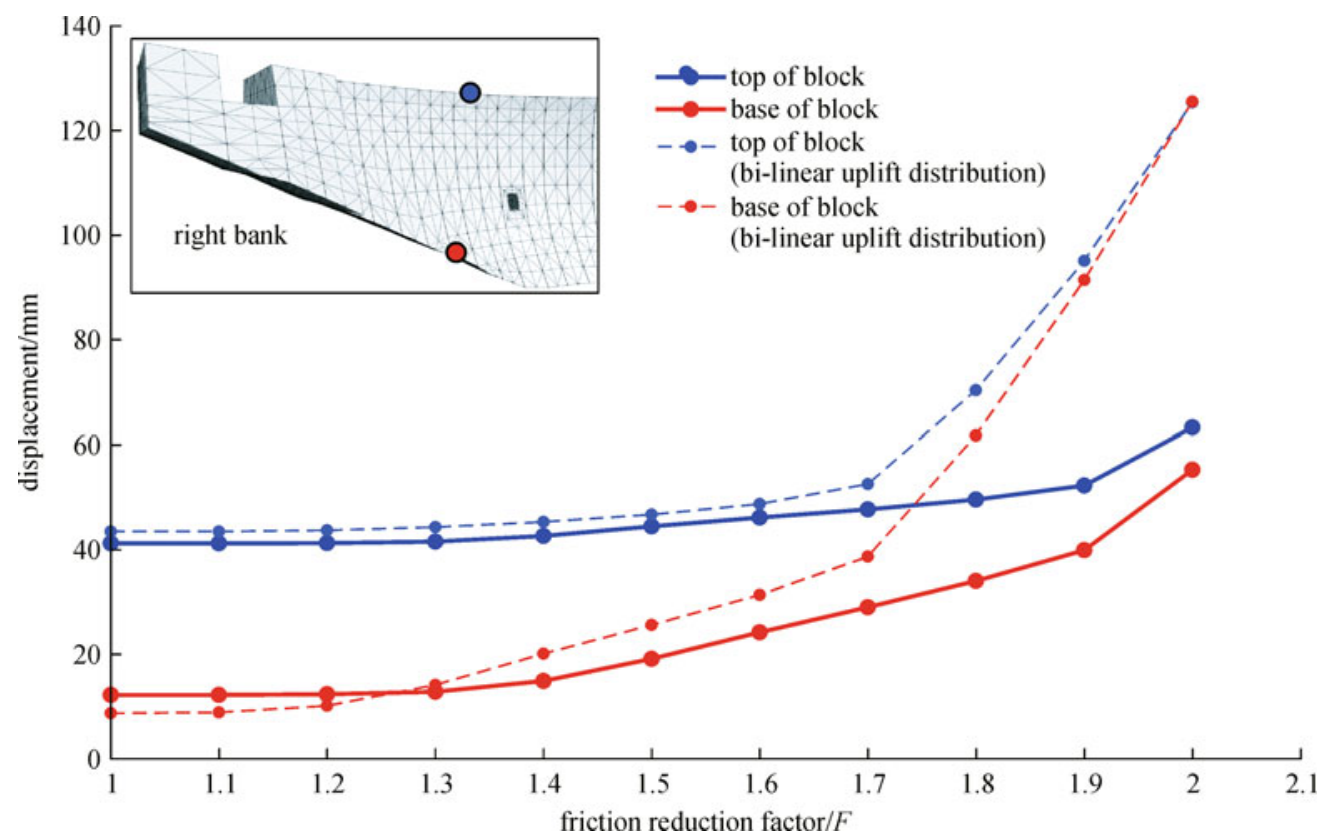

Fig. 11 Variation in displacements at the top and at the base of two different blocks on the right bank, during the process of friction angle reduction, with different uplift distributions

numerical model to look at the possible foundation failure scenario of sliding along the dam/foundation interface. In this model, the dam/foundation interface, arch dam contraction joints and two hypothetical joints between the grout curtain and the rock mass were simulated. Water pressures within the rock mass were considered, in order to analyze shear displacement in terms of effective stresses, with the reservoir at the retention water level. Applied uplift pressures were either the result of a hydraulic analysis or those usually prescribed in design codes, assuming a bi-linear distribution to account for the relief drains. Dam safety was evaluated using a process of reduction of strength characteristics, with the aim of calculating the minimum safety factors that ensure stability.
For the assessment of the failure scenario along the foundation joint the contribution of both cohesion and tensile strength was neglected, as prescribed in current Portuguese Regulation for the safety of dams, and the tangent of the friction angle was divided by an increasing factor $F$ up to the value of 2.0. Two different situations were analyzed, in the first of which an efficient drainage system was assumed. In this case, the system is still stable for $F=2.0$, however there is a substantial increase in the rate of displacements for $F=1.9$, corresponding to a friction angle of $27.8^{\circ}$. In the second scenario, with no drainage system, there is a sudden increase in dam displacements after $F=1.3$, corresponding to a friction angle of $37.6^{\circ}$. This situation is particularly penalizing for this dam, because of the large distance between the toe of 
the dam and the location where the downstream reservoir conditions are established.

The study presented here shows that the hydraulic analysis carried out provides a realistic water pressure pattern, as it takes into account the loss of hydraulic head at the grout curtain area and the different hydraulic and geotechnical conditions at the base of each dam block. This may be particularly relevant in dams with complex hydraulic boundary conditions, for instance in dams with more than one grout or drainage curtain, with drainage galeries in the abutments or adjacent structures, like the powerhouse at the toe of Alqueva dam. Comparison between the results obtained using the calculated uplift pressures and those commonly used in concrete dam design (bi-linear uplift pressure distribution) led to the conclusion that they may be quite different.

Further work is underway in order to calculate safety factors using the procedure presented in this paper and a model which takes into account the main faults and sets of rock joints within the dam foundation, in addition to the discontinuities simulated in the model presented here. In this case, hydrostatic pressure is likely to have a great influence on slope instability mechanisms and on the safety factor, and thus the importance of carrying out hydraulic analysis will probably be even more evident.

Acknowledgements Thanks are due to EDIA, Empresa de Desenvolvimento e Infra-Estruturas do Alqueva, SA for permission to publish data relative to Alqueva dam.

\section{References}

1. Barla G, Bonini M, Cammarata G. Stress and seepage analyses for a gravity dam on a jointed granitic rock mass. In: Proceedings of the 1st International UDEC/3DEC Symposium. Bochum, 29 September - 1 October 2004, 263-268

2. Gimenes E Á, Fernández G. Hydromechanical analysis of flow behaviour in concrete gravity dam foundations. Canadian Geotechnical Journal, 2006, 43(3): 244-259

3. Lemos J V. Modelling and failure analysis in rock engineering, Research Programme. LNEC, Lisboa, 1999

4. Lemos J V, Antunes N S. Modelling of arch dam foundation failure scenarios - case studies of Baixo Sabor and Alto Ceira dams. Dam Engineering, 2011, XXI(4): 299-312

5. Feng J, Wei H, Pan J, Jian Y, Wang J, Zhang C. Comparative study procedure for the safety evaluation of high arch dams. Computers and Geotechnics, 2011, 38(3): 306-317

6. Itasca, 3DEC - 3 Dimensional Distinct Element Code. Version 4.2. User's Manual, Itasca Consulting Group, Minneapolis, 2006

7. Farinha M L B, Lemos J V, Maranha das Neves E. Numerical Modelling of borehole water-inflow tests in the foundation of the Alqueva arch dam. Canadian Geotechnical Journal, 2011, 48(1): 7288

8. European Club of ICOLD. Sliding Safety of Existing Gravity Dams Final Report. Report of the European Working Group. 2004

9. Farinha M L B, Lemos J V. Stress-dependent permeability in the foundation of Alqueva dam. In: Proceedings of the 2nd International Conference on Long Term Behaviour of Dams. Graz, Austria, 12-13 October, 2009, 125-130 